\title{
Aronia Melanocarpa Antioxidant Potential against Chromium VI Induced Morphological Changes in Endocrine Pancreas
}

\author{
Jelena SAVICI*, Diana BREZOVAN, Florin MUSELIN \\ Faculty of Veterinary Medicine, University of Agricultural Sciences and Veterinary Medicine of \\ Banat"King Michael I of Romania" Timisoara, Calea Aradului nr. 119, 300654, Timisoara, Romania \\ *corresponding author: jelenarankov@yahoo.com
}

Bulletin UASVM Veterinary Medicine 73(2) / 2016,

Print ISSN 1843-5270; Electronic ISSN 1843-5378

DOI:10.15835/buasvmcn-vm: 12178

\begin{abstract}
Hexavalent chromium, known as strong oxidizing agent, enters the cells easily and generates reactive oxygen species. The data from literature showed that $\mathrm{Cr}$ VI is toxic for liver, kidney, skin, and nervous system, female and male reproductive systems. However, chromium effects on pancreas are less studied.

Aronia melanocarpa fruits are rich in phenolic constituents: anthocyanins, procyanidins and phenolic acids, which demonstrated to have anti-oxidative, anti-viral, anti-mutagenic, anti-cancer, anti-inflammatory activities.

Considering the previously mentioned, the aim of present study had been to see if $\mathrm{Cr}$ VI induces structural changes in pancreas, given chromium property of inducing ROS formation in cells, and if Aronia extract can play a protective role.

For this study were used white Wistar rats divided in 5 groups. Exposed as follows: C - control - distilled water, $\mathrm{Cr}$ group - potassium dichromate, hexavalent chromium compound, in distilled water, $75 \mathrm{ppm}$ for three months; CrA group - 75 ppm Cr VI + extract of A. melanocarpa for three months; $\mathrm{Cr}_{2}$ group - $75 \mathrm{ppm} \mathrm{Cr} \mathrm{VI}$ for three months followed by one month of distilled water; $\mathrm{CrA}_{2}$ group $75 \mathrm{ppm} \mathrm{Cr}$ VI for three months followed by one month of extract of A. melanocarpa. At the end of exposure period, we collected pancreas and prepared it for histological analysis.

Hexavalent chromium administration induced morphological and functional changes in endocrine pancreas cells: size and number reduction of Langerhans islets and presence of degenerative lesions. Experimental group that received Cr VI combined with aqueous extract of Aronia presented almost normal architecture of endocrine cells.
\end{abstract}

Keywords: Aronia melanocarpa, chromium, pancreas

\section{INTRODUCTION}

Chromium is a naturally occurring element, which can exist in several oxidation states. Trivalent (III) and hexavalent (VI) form are thought to be the most biologically significant. Trivalent chromium is an essential nutrient, while hexavalent form of chromium is highly toxic. Cr VI is commonly used in more than 50 industries, the basic ones being metallurgical, chemical and refractory (Stoecker, 2004). While hexavalent chromium can easily cross the cellular membrane, using nonspecific anion carriers, trivalent chromium lack this property.
Inside the cell, $\mathrm{Cr}$ VI is reduced by intracellular reductants to chromium intermediates $\mathrm{Cr} \mathrm{V}$ and $\mathrm{Cr}$ IV, and ultimately to stable form of Cr III, which forms mutagenic Cr-DNA adducts responsible for chromium toxic and mutagenic capacities. This reduction process generates reactive oxygen species (ROS) such as superoxide $\left(0^{-}\right)$, hydroxyl $\left(\mathrm{OH}^{-}\right)$and hydrogen peroxide $\left(\mathrm{H}_{2} \mathrm{O}_{2}\right)$, all being the sources of hydroxyl radicals (Zhitkovich, 2011).

Thus, hexavalent chromium is 100-1000 times more toxic than its trivalent form (Stoecker, 2004). $\mathrm{Cr} \mathrm{VI}$ is strong oxidizing agent known for toxic and 
carcinogenic effects in humans and animals. US EPA (1987) listed this metal among the 126 priority pollutants. In addition, it is listed among the 25 most hazardous substances posing the greatest risk to human and ecosystem health (USDHHSUSEPA, 1987). Exposure to hexavalent form of chromium can induce acute and chronic toxicity, neurotoxicity, dermatotoxicity, genotoxicity, carcinogenicity, immunotoxicity and general environmental toxicity (Von Burg and Liu, 1993). However, there are only a few studies regarding hexavalent chromium effects on pancreas.

Trivalent chromium is essential for maintenance of human normal physiology, due to its capacity to regulate insulin and blood glucose levels by stimulating insulin signaling pathways and metabolism by up-regulating glucose transporter (GLUT4) translocation in muscle cells (Qiao et al., 2009). Likewise, trivalent form of chromium intervenes in optimal cell uptake of glucose (Khan and Awan, 2014 and Tudan et al., 2011). However, in case of trivalent chromium deficiency, blood glucose levels elevate and if this state persists, it may lead to the onset of diabetes (Wiernsperger and Rapin, 2010).

Aronia melanocarpa (black chokeberry) is a member of the Rosaceae family and originates from North America, where its fruits have been used in folk medicine. Later, in $20^{\text {th }}$ century chokeberry was introduces in Eastern Europe and Soviet Union. Now this shrub is cultivated for production of juice, jam, wine and food colorants. It was demonstrated that Aronia extracts and juices possess anti-oxidative, antiviral, antimutagenic, anti-cancer, hepato protective, antiinflammatory, gastroprotective and anti-diabetic activities (Chrubasik et al., 2010, Kokotkiewicz et al., 2010, Kulling and Rawel, 2008). Beneficial effects of Aronia berries are due to their high content of polyphenols, especially anthocyanin's, with antioxidant activity. They possess the highest antioxidant activity among berries and other fruits investigated until now (Kulling and Rawel, 2008, Zheng and Wang, 2003).

Chokeberry fruits have the highest content of phenolic constituents than most other blackberries, respectively: anthocyanins, procyanidins and phenolic acids. Free radical formation is directly linked to lipid peroxidation, implicated in pathogenesis of a variety of diseases: cellular aging, mutagenesis, inflammation, carcinogenesis, coronary heart disease and diabetes. Thus, substances that can inhibit ROS could have a positive effect on all enumerated states above (Bräunlich et al., 2013, Kulling and Rawel, 2008).

The aim of this study was to determinate if $\mathrm{Cr}$ VI induces structural changes in pancreas, given its ability to enter the cells and to easily produce ROS, and if Aronia extract can play a protective role, given its demonstrated antioxidant activity.

\section{MATERIALS AND METHODS}

Animals

The study was performed on adult male Wistar rats $(n=35)$ weighting $220-240 \mathrm{~g}$ that were purchased from a licensed breeder. Animals housed in plastic cages at standard laboratory conditions under a 12-h light/dark cycle and at a constant temperature $\left(25 \pm 2^{\circ} \mathrm{C}\right)$ were provided free access to food and water. The animals were handled according to the standard guide for the care and use of laboratory animals.

\section{Plant material}

The dried Aronia berry was purchased from natural plant shop. To obtain aqueous extract, classic extraction was performed by mixing dried berries skin and seeds with distilled water in water/volume ratio of $0.25 / 10(\mathrm{w} / \mathrm{v})$. After heating at $90^{\circ} \mathrm{C}$ for 10 minutes the mixture was filtered (Alupului et al., 2009, Muselin et al., 2015).

\section{Experimental model}

The rats were divided in five groups as follows: $\mathrm{C}$ - control group receiving distilled water;

$\mathrm{Cr}$ - group receiving potassium dichromate, which is hexavalent chromium compound, in distilled water, at $75 \mathrm{ppm}$ for three months - level representing 3x LOAEL (US EPA, 2001), and is dose at which damages were the most severe as the anterior studies have shown (Rankov et al., 2009, Rankov and Trif, 2010a, Rankov and Trif, 2010b, Rankov et al., 2010a, Rankov et al., 2010b, Rankov et al., 2010c, Trif and Rankov, 2010);

CrA - group receiving for three months Cr VI 75 ppm in distilled water + Aronia melanocarpa 2,5 $\%$ aqueous extract;

$\mathrm{Cr}_{2}$ - group receiving for three months $75 \mathrm{ppm} \mathrm{Cr}$ VI in distilled water followed by one month of distilled water alone; 
$\mathrm{CrA}_{2}$ - group receiving for three months $75 \mathrm{ppm}$ $\mathrm{Cr} \mathrm{VI}$ in distilled water followed by one month of Aronia melanocarpa 2,5\% aqueous extract.

At the end of experimental period, the rats were sacrificed following the standards of national and international law regarding care and use of laboratory animals.

For histological assessment, pancreas tissue was dissected out from each experimental group. The tissue samples were fixated using Bouin's Hollande fixative for 18 hours (Humanson, 1972) and then processed via the paraffin wax embedding method. The paraffin embedded-samples were sectioned at 5-micron thickness using microtome (Cut 4062 Slee Mainz, Germany). The slides stained by Hematoxylin - Eosin and trichrome Mallory method were examined on Olympus microscope CX 41 with digital photo camera and software for image analysis QuickPHOTO Micro 2.2.

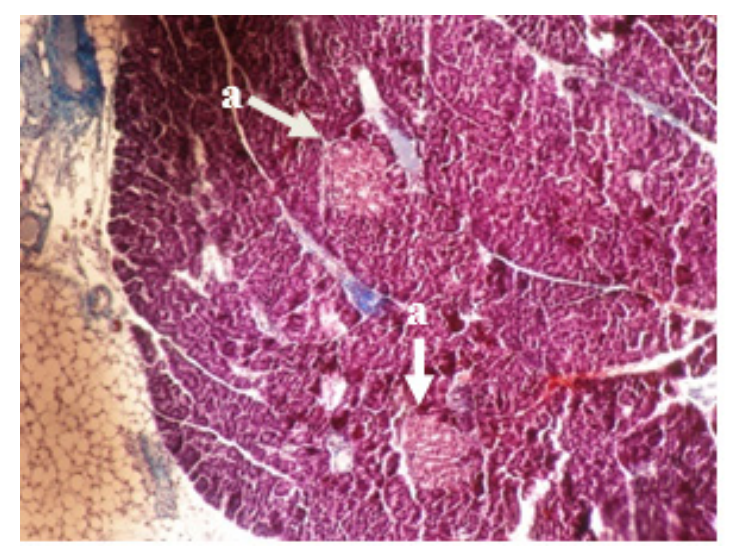

\section{RESULTS AND DISCUSSION}

Microscopic examination of the pancreas from control group revealed the morphologically normal aspect with compact arrangement of the endocrine cells in the islets of Langerhans and exocrine cells, grouped in serous acini (Fig. 1 A, B).

Histological slides of pancreas from individuals exposed for three months to hexavalent chromium showed reduction in islet dimensions and number. Endocrine cells from islets were found to be reduced in number. In some cases, the cells degenerated leaving atrophied islets. Vacuolization of the endocrine cells was also present. Microscopic examination highlighted the dilatation of connective tissue septa. Capillaries and arterioles were dilated (Fig. 2 A, B).

Pancreas section obtained from rats treated for three months with $75 \mathrm{ppm}$ of $\mathrm{Cr}$ VI combined with aqueous extract of Aronia melanocarpa

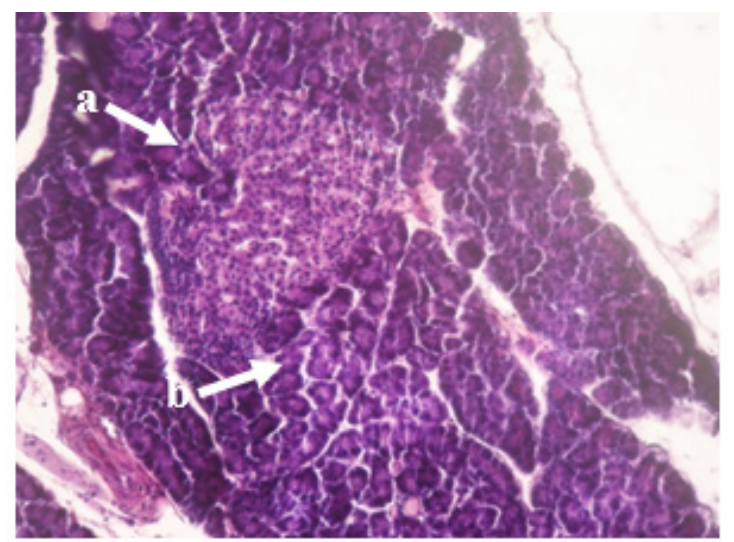

Fig. 1. A and B: Histological section trough pancreas of the control group: a - normal structural aspects of Langerhans islets, b - pancreatic acini, trichrome Mallory stain, 10X and 20X ob.
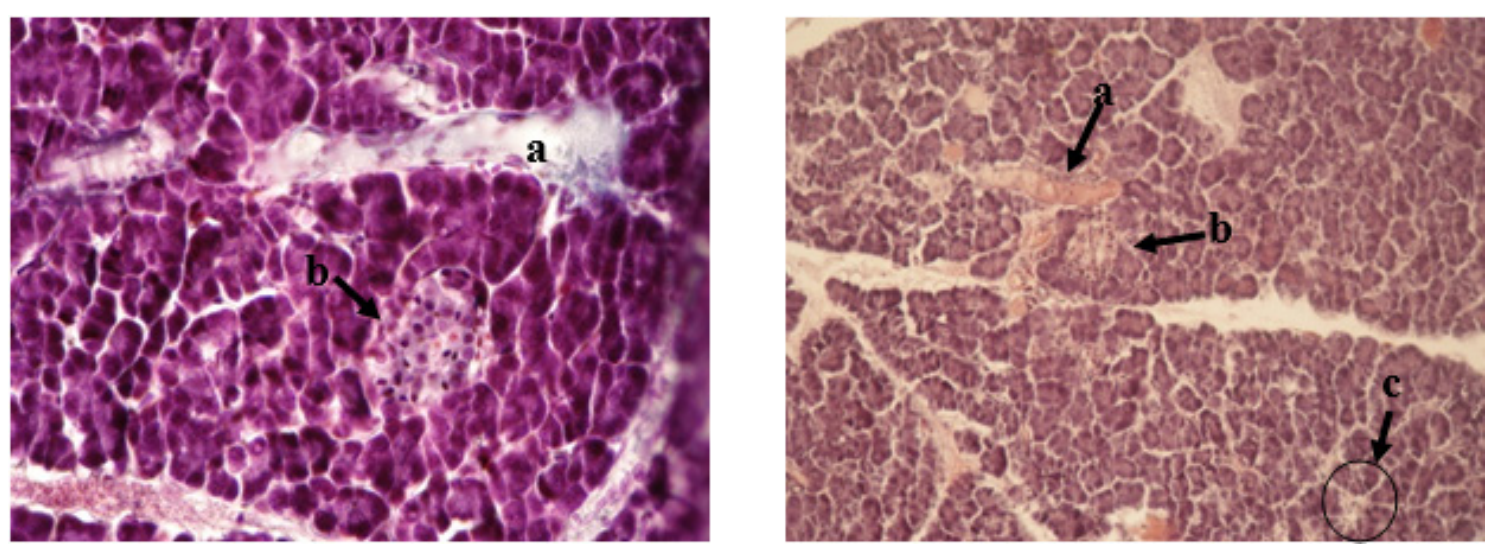

Fig. 2. A and B: Histological section trough pancreas of the Cr group: a - dilated blood vessel, b - small vacuolated Langerhans islets, c - atrophied islet, trichrome Mallory stain, 40X ob. and H\&E stain, 20X ob. 
presented compact arrangement of endocrine cells grouped in large Langerhans islets, situated near blood vessels (Fig. 3). Pancreatic sections from this group showed dilated and congested blood vessels.

In the case of rats from $\mathrm{Cr}_{2}$ group, treated with hexavalent chromium for three months followed by one month of distilled water, microscopic examination emphasized reduction of Langerhans islet number (there were histological slides with total absence of endocrine cells), or large Langerhans islet with structural architecture altered. Endocrine cells presented degenerative lesions like vacuolization, reduction of number and necrosis.
Moreover, disruption of endocrine islets associated with disorientation of cells was observed. Also there were no clearly defined edges between endocrine and exocrine pancreas. Langerhans islets with undefined edges presented blank spaces, given by degeneration and removal of endocrine cells. Interlobular connective tissue dilatation was noticed as well (Fig. 5).

Microscopic examination of pancreas from rats treated with $75 \mathrm{ppm}$ of $\mathrm{Cr}$ VI for three months followed by aqueous extract of Aronia melanocarpa for one month revealed large, compact Langerhans islets, surrounded by normal glandular acinar cells (Fig. 6 A, B).

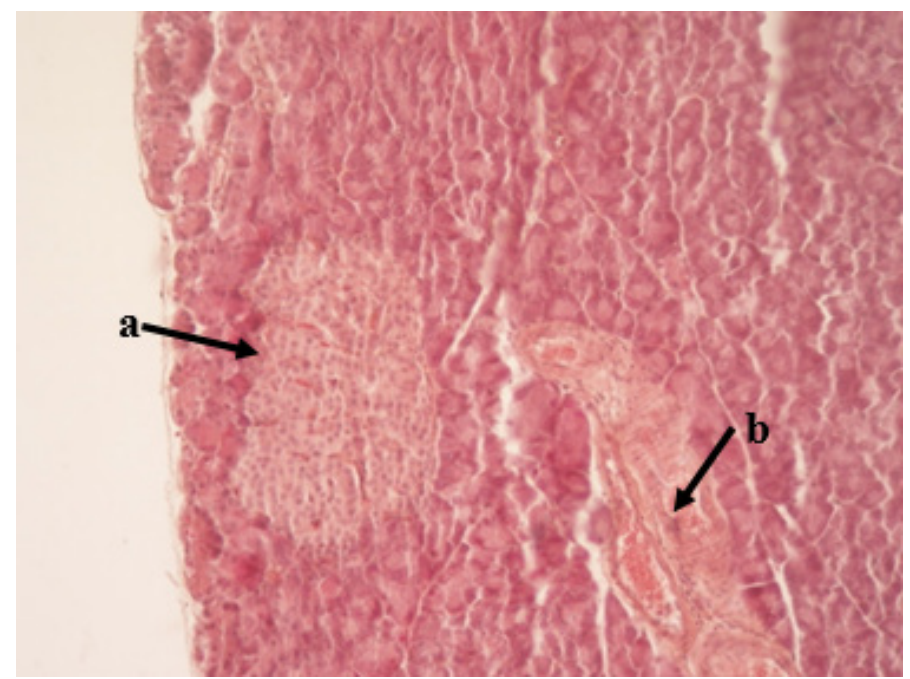

Fig. 3. Histological section trough pancreas of the CrA group: a - Langerhans islet, b - blood vessel, H\&E stain, 20X ob.
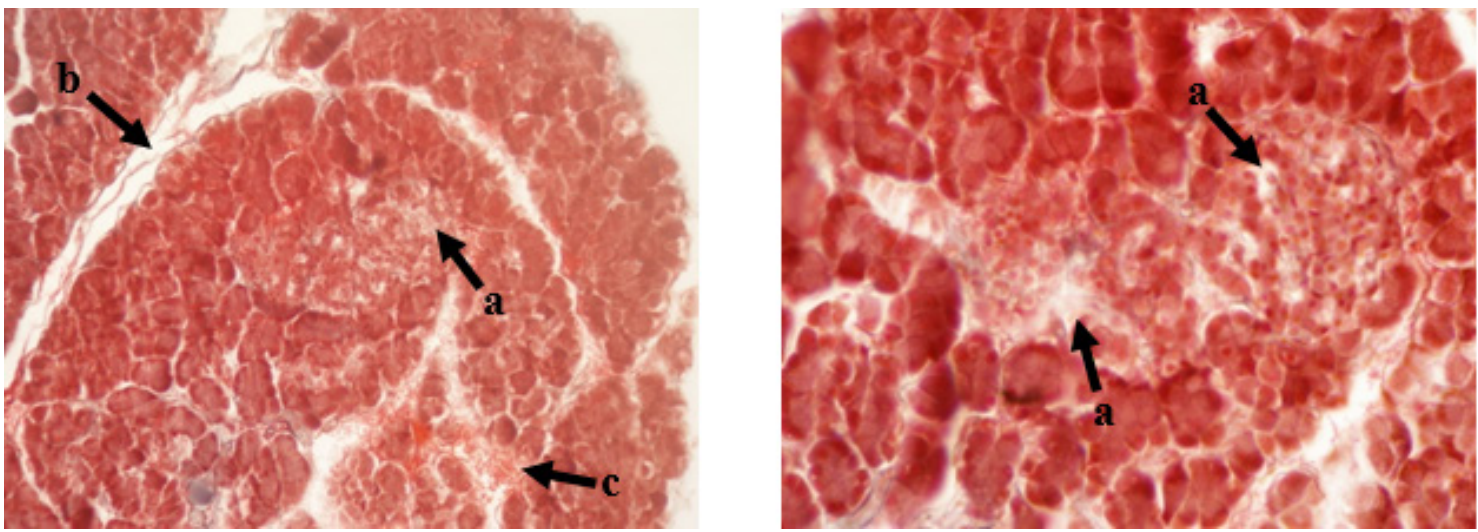

Fig. 4. A and B: Histological section trough pancreas of the $\mathrm{Cr}_{2}$ group: a - degenerated, vacuolated endocrine cells, b - dilatation of connective interlobular tissue, c - congestion, trichrome Mallory stain, 10X and 40X ob. 
However, some islets of Langerhans revealed blank spaces within, significantly smaller when compared with pancreas of rats treated only with chromium.

Dilatation of blood vessels was present in this experimental group too, but in this case, it was the predominant phenomena. Capillaries appear dilated and engorged with blood; erythrocytes were well stained and individualized indicating hyperemia, which can be considered a compensatory and/or repairing phenomenon that appears in response to increased demands for nutrients and oxygen, increases cellular metabolism, hastens movements of metabolites into area and supports cellular proliferation.
Guria et al. (2016) described the similar histological finding after exposing mice to chromium oxide, a hexavalent chromium compound. El-Saad et al. (2010) showed that intraperitoneally administration of potassium dichromate induces in pancreatic $\beta$ cells degranulation, nuclear membrane break down, cell membrane rupture and swelling of mitochondria. All these changes induced by oxidative stress, were reduced by administration of $\mathrm{N}$-acetylcysteine an Allium plant compound.

Hyperemia was described on histological slides of pancreas from rats receiving chromium. Also, the most severe lesions of endocrine cells, going from vacuolation to necrosis (progressive

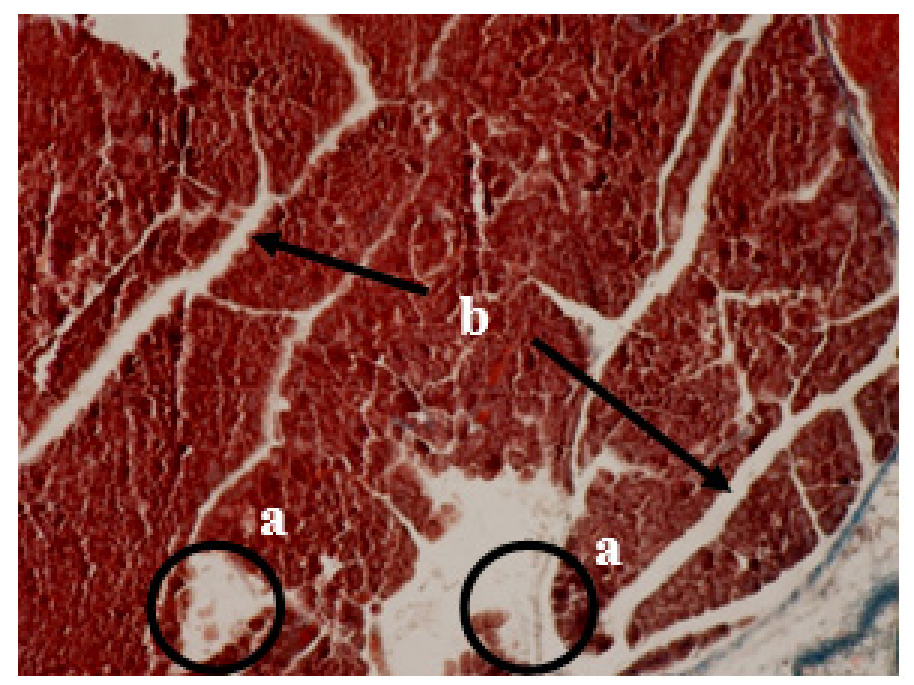

Fig. 5. Histological section trough pancreas of the $\mathrm{Cr}_{2}$ group: $\mathrm{a}$ - atrophied islet, $\mathrm{b}$ - dilatation of connective tissue, trichrome Mallory, stain, 10X ob.
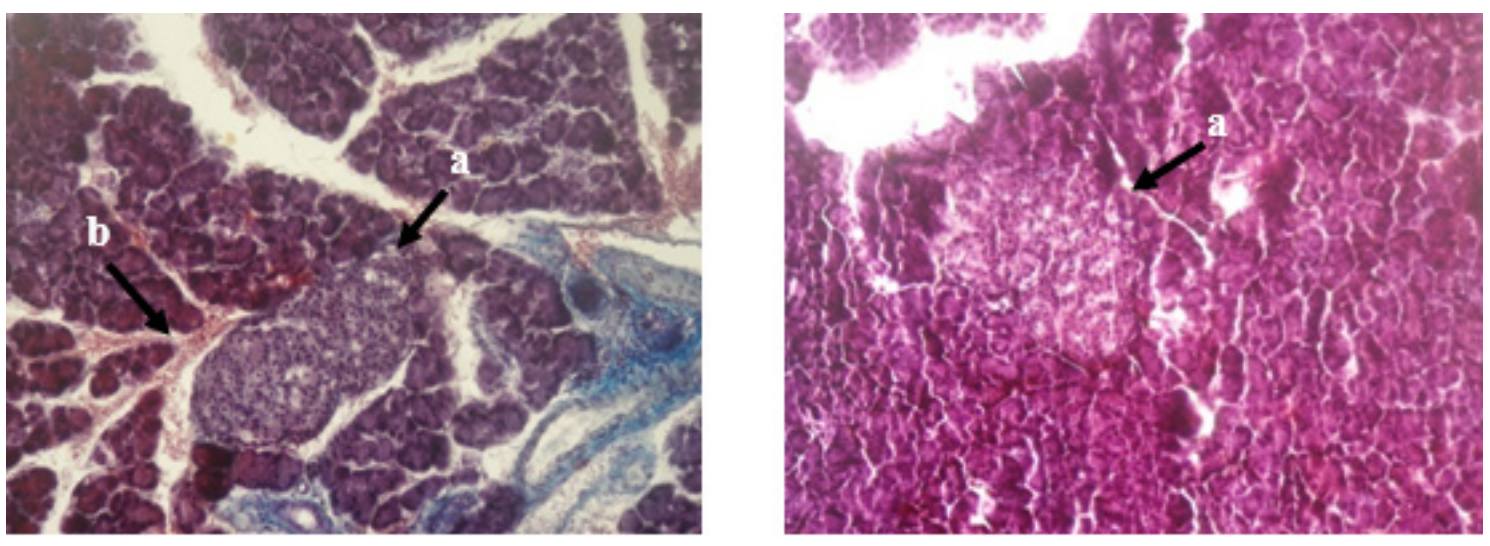

Fig. 6. A and B: Histological section trough pancreas of the $\mathrm{CrA}_{2}$ group: a - large Langerhans islet, b - hyperemia, trichrome Mallory stain, 20X ob. 
destruction), are described in chromium treated groups. The changes of Langerhans islet's architecture reflect an inhibition in insulin synthesis and secretion as reported in diabetic animals (Zhou et al., 2009).

That means that hexavalent chromium enters the pancreas cells as well, and by its reduction, generates ROS. Redox disturbances have negative effects on body systems through formation of ROS, responsible for proteins and lipids destruction and DNA oxidation (Halliwell and Gutteridge, 1990). Chromium does not generate free radicals directly, it produces indirectly radicals as superoxide, nitrogen species like peroxynitrite, nitric oxide and hydroxyl causing damage consistent with oxidative stress (Pritchard et al., 2000). These radicals attack the cell membrane and lead to the destabilization and disintegration of the cell membrane because of lipid peroxidation (Susa et al., 1996).

One of the main approaches used to lessen $\mathrm{Cr}$ VI induced toxicity is the use of powerful antioxidant agents. Aronia melanocarpa is kwon for its antioxidant activity. It can be observed that, in the experimental groups that received aqueous extract from this plant, lesions induced by $\mathrm{Cr}$ VI were reduced, and hyperemia extended. Based on these findings, it can be attributed to Aronia melanocarpa the property to alleviate $\mathrm{Cr}$ VI induced degenerative lesions in pancreatic endocrine cells.

\section{CONCLUSION}

Based on finding of this study it can be concluded that chromium in its hexavalent form has negative impact on endocrine pancreas, producing structural alterations in Langerhans islet cells, which in turn lead to functional alteration: insulin synthesis and secretion.

When combined with aqueous extract of Aronia melanocarpa, chromium oxidant activity is reduced and resulting morphological alterations are minimized.

\section{ACKNOWLEDGMENTS}

This research work was carried out with the financial support of the project "The use of some antioxidants from plants to reduce the effects of oxidative stress induced by chronic exposure to hexavalent chromium on the endocrine glands (endocrine pancreas, adrenal gland) in rats", no. 2758, Internal competition 2015 USAMVBT.

We express our regards to the the project „Development of infrastructure for research, education and services in the fields of veterinary medicine and innovative technologies for RO 05", code SMIS-CSNR 2669 for providing infrastructure necessary conducting this study.

\section{REFERENCES}

1. Alupului A, Calinescu I, Lavric V (2009). Ultrasonic vs. microwave extraction intensification of active principles from medicinal plants. AIDIC Conference Series 9:1-8, doi: 10.3303/ACOS0909001.

2. Anatoly Zhitkovich (2011). Chromium in drinking water: sources, metabolism and cancer risks. Chem Res Toxicol 24:1617-1629.

3. Bräunlich $M$, Slimestad $R$, Wangensteen $H$, Brede $C$, Malterud KE, Barsett H (2013). Extracts, anthocyanins and procyanidins from Aronia melanocarpa as radical scavengers and enzyme inhibitors. Nutrients 5:663-678.

4. Chrubasik C, Li G, Chrubasik S (2010). The clinical effectiveness of chokeberry: a systematic review. Phytother Res 24:1107-1114.

5. El-Saad AM, Abdel-Moneim AM, Abdel-Karim HM (2010). $\mathrm{N}$-acetylcysteine an Allium plant compound protects against chromium (VI) induced oxidant stress and ultrastructural changes of pancreatic beta-cells in rats. Journal of Medicinal Plants Research. 4(21): 2290-2297

6. Guria Sr, Chakraborty B, Banerjee M (2016). Chromium (VI) induced histological changes of pancreatic islets and liver: a preliminary study of metal induced diabetes mellitus. The Experiment, 35(2): 2171-2181.

7. Halliwell B, Gutteridge JM (1990). Role of free radicals and catalytic metal ions in human disease: An overview. Meth. Enzymol. 186: 1-85.

8. Humanson G.L (1972). Fixation, p. 3-24. In: Animal tissue techniques. 3rd ed. W.H. Freeman \& Co Ltd, San Francisco.

9. Khan AR, Awan FR (2014). Metals in the pathogenesis of type 2 diabetes. J Diabetes Metab Disord. 13: 16.

10. Kokotkiewicz A, Jaremicz Z, Luczkiewicz M (2010). Aronia plants: a review of traditional use, biological activities, and perspectives for modern medicine. J Med Food 13:255-269.

11. Kulling SE, Rawel HM (2008). Chokeberry (Aronia melanocarpa) - A review on the characteristic components and potential health effects. Planta Med 74:1625-1634.

12. Muselin F, Brezovan D, Savici J, Cristina RT, Dumitrescu E, Doma AO, Morar D, Trif A (2015). The use of Yellow Dock (Rumex crispus L.) and Goji Berry (Lycium barbarum L.) in alloxan induced diabetes mellitus in rats. Scientific Papers: J Anin Sci Biotechnol, 48(1):373-376.

13. Pritchard KA, Ackerman A, Kalyanaraman B (2000). Chromium VI increases endothelial cell expression of ICAM-1 and decreases nitric oxide activity. J. Environ Pathol Toxicol Oncol. 19: 251-260. 
14. Qiao W, Peng Z, Wang Z, Wei J, Zhou A (2009). Chromium improves glucose uptake and metabolism through upregulating the mRNA levels of IR, GLUT4, GS, and UCP3 in skeletal muscle cells. Biol Trace Elem Res. 131(2): 133142.

15. Rankov J, Igna V, Trif Al (2009). Potassium dichromate chronic exposure impact on rat sperm quality. Scientific Works C Series. LV(3): 221-226.

16. Rankov J, Trif A (2010a). Consequences of six months potassium dichromate intake on seric testosterone and LH level in male rats. Scientific Works C Series. LVI (1):150-154.

17. Rankov J, Trif A (2010b). The consequences of hexavalent chromium compound six months exposure on some morphological biomarkers in male rats. Lucr șt. Med. Vet. 53(12).3: 504-508.

18. Rankov J, Trif A, Brezovan D (2010a). Six months exposure to potassium dichromate outcomes on histoarchitecture of genital organs and sexual accessory glands in male rats. Lucr şt MedVet. 53(12). 3:509-512.

19. Rankov J, Trif A, Brezovan D, Muselin F (2010b). Potassium dichromate impact on male reproductive integrity biomarker in rat. Two generation study. J Anim Sci Biotechnol. 43(1):224-229.

20. Rankov J, Trif A, Steliac (marr. Munteanu) S (2010c). Testosterone and LH seric level dynamics in male rats after potassium dichromate intake (two generation study). J Anim Sci Biotechnol. 43(1):230-233.

21. Stoecker Barbara (2004). Chromium p. 709-729, In: Elements and their compounds in the environment $2^{\text {nd }}$ edition, Ed. Wiley - VCN Verlag GmbH \& Co. KGaA, Weinheim, Germany.
22. Susa N, Ueno S, Furukawa Y, Sugiyama M (1996). Protective effect of vitamin E on chromium (VI)-induced cytotoxicity and lipid peroxidation in primary cultures of rat hepatocytes. Arch. Toxicol. 71: 20-24.

23. Trif A, Rankov J (2010). Dynamics of biochemical biomarkers for testicular function consecutive rat exposure to potassium dichromate (three generation experiment). Works C Series. LVI (3-4):434-441.

24. Tudan C, Weber FX, Levine KE (2011). The status of trace elements analysis in biological systems. Bioanalysis. 3(15):1695-1697.

25. USDHHS-USEPA (1987). Notice of the first priority list of hazardous substances that will be the subject of toxicological profiles. Federal Register. 52:12866-12874.

26. USDHHS-USEPA (2001). Toxicological Profile for Chromium http://www.epa.gov.

27. Von Burg R, Liu D (1993). Chromium and hexavalent chromium. J App Toxicol. 13(3):225-230.

28. Wiernsperger N, Rapin J (2010). Trace elements in glucometabolic disorders: an update. Diabetol Metab Syndr. 2 (70): 1-9.

29. Zheng W, Wang SY (2003). Oxygen radical absorbing capacity of phenolics in blueberries, cranberries, chokeberries, and lingonberries. J. Agric. Food Chem. 51:502-509.

30. Zhou J, Zhou S, Tang J, Zhang K, Guang L, Huang Y, Xu Y, Ying Y, Zhang L and Li D (2009). Protective effect of berberine on beta cells in streptozotocin- and high carbohydrate/ high-fat diet-induced diabetic rats. European J. Pharmacol. 606: 262-268. 